\title{
Transanal Endoscopic and Transabdominal Robotic Total Mesorectal Excision for Mid-to-Low Rectal Cancer: Comparison of Short-term Postoperative and Oncologic Outcomes by Using a Case-Matched Analysis
}

\author{
Ki Young Lee, Jung Kyoung Shin, Yoon Ah Park, Seong Hyeon Yun, Jung Wook Huh, Yong Beom Cho, \\ Hee Cheol Kim, Woo Yong Lee \\ Department of Surgery, Samsung Medical Center, Sungkyunkwan University School of Medicine, Seoul, Korea
}

Purpose: This study aimed to compare short-term postoperative and oncologic outcomes of a transanal endoscopic total mesorectal excision (TME) to those of a transabdominal robotic TME.

Methods: A total of 62 patients with rectal cancer underwent transanal $(n=26)$ or robotic $(n=36)$ TME between June 2013 and December 2014. After case-matching by tumor location and TNM stage, 45 patients were included for analysis. The median follow-up period was 21.3 months. Operative, histopathologic and postoperative outcomes and recurrences were analyzed.

Results: Patients younger than 60 years of age were more frequently observed in the robotic TME group $(75.0 \%$ vs. $47.6 \%$, $\mathrm{P}=0.059$ ), but tumor location, $\mathrm{cT}$ and $\mathrm{cN}$ category, and preoperative chemoradiotherapy were not different between the 2 groups. Estimated blood loss was greater in the transanal group $(283 \mathrm{~mL}$ vs. $155 \mathrm{~mL}, \mathrm{P}=0.061)$; however, the operation time and the rate of a diverting ileostomy and subsequent ileostomy repair were not different between the groups. The proximal resection margin was longer in the transanal TME group $(20.8 \mathrm{~cm} \pm 16.0 \mathrm{~cm}, \mathrm{P}=0.030)$, but the distal resection margins, involvements of the circumferential resection margin, TME quality, numbers of retrieved lymph nodes, postoperative complications, including anastomotic leak and voiding difficulty, and recurrence rates for the 2 groups were not statistically different.

Conclusion: Transanal endoscopic and transabdominal robotic TME showed similar histopathologic and postoperative outcomes with the exception of the estimated blood loss and the proximal resection margin for a select group of patients.

Keywords: Rectal neoplasms; Transanal endoscopic total mesorectal excision; Transabdominal robotic total mesorectal excision

\section{INTRODUCTION}

Recent randomized clinical trials that compared laparoscopic and open surgery for the treatment of rectal cancer have failed to

Received: August 31, 2017 - Accepted: October 24, 2017

Correspondence to: Yoon Ah Park, M.D.

Department of Surgery, Samsung Medical Center, Sungkyunkwan University

School of Medicine, 81 Irwon-ro, Gangnam-gu, Seoul 06351, Korea

Tel: +82-2-3410-6546, Fax: +82-2-3410-6980

E-mail:yapark74@gmail.com

ORCID code: https://orcid.org/0000-0002-2328-1613

(c) 2018 The Korean Society of Coloproctology

This is an open-access article distributed under the terms of the Creative Commons Attribution NonCommercial License (http://creativecommons.org/licenses/by-nc/4.0) which permits unrestricted noncommercial use, distribution, and reproduction in any medium, provided the original work is properly cited. demonstrate the noninferiority of the laparoscopic technique compared to the open approach with the primary end-point being a composition of circumferential resection margin (CRM) greater than $1 \mathrm{~mm}$, tumor-free distal resection margin (DRM), and completeness of the total mesorectal excision (TME) [1, 2]. According to subgroup analyses, laparoscopic surgery is less successful for patients with a higher body mass index (BMI), a large tumor, or a history of having undergone neoadjuvant chemoradiotherapy. Although the long-term oncologic outcomes should be followed up, these results suggest a need for improved minimally invasive surgical techniques, especially for high-risk groups of patients.

Robotic surgery has been increasingly applied to the treatment of rectal cancer with the expectation of overcoming the limitations 
of conventional laparoscopic surgery by virtue of the technical advantages of surgical robots, such as an operator-controlled stable visual field, 3-dimensional imaging, operator-controlled constant counter-traction with a third robotic arm, and articulated tips of instruments. Robotic rectal cancer surgery is known to be associated with a lower conversion rate compared to the conventional laparoscopic technique [3,4]. Although a few comparative studies have reported that robotic surgery showed higher rates of complete quality of TME specimens and shorter hospital stay compared with the laparoscopic approach [5-7], most studies did not find significant differences with respect to histopathologic and postoperative recovery outcomes [8-11]. Several studies reported that the robotic approach allowed earlier recovery of postoperative voiding and sexual functions; however, the evidence was insufficient to make a confirmative conclusion [12-14]. At the present time, these results seem not justify the higher cost and the longer operation time of robotic surgery.

Another surgical option of rectal cancer surgery that has been receiving considerable attention is transanal endoscopic TME. In this technique, the rectum is dissected through the anal canal in a caudal-to-cephalad direction by using conventional laparoscopic instruments [15-17]. Transanal endoscopic TME is regarded to have the advantages that it does not require any specific or expensive instruments and that 2 surgical teams can carry out transabdominal colon mobilization and transanal TME (taTME) simultaneously, leading to a reduction in operation time $[18,19]$. In addition, several studies demonstrated that taTME is associated with excellent TME quality and a low rate of involvement of the CRM $[17,19,20]$.

Nevertheless, no studies comparing these 2 alternative surgical options, transanal endoscopic TME and transabdominal robotic TME (robTME), to conventional laparoscopic surgery for the treatment of rectal cancer have been reported. Thus, the aim of this study was to do such a comparison with respect to short-term postoperative and oncologic outcomes.

\section{METHODS}

Between June 2013 and December 2014, a total of 68 patients with a primary rectal adenocarcinoma underwent restorative proctectomy by taTME or robTME at one single center. After exclusion of 6 patients who had stage IV disease, 26 patients who had undergone taTME and 36 patients who had undergone robTME were included. The 2 groups of patients were not comparable in terms of tumor location because the frequency of low rectal cancer was significantly higher in the robTME group. Therefore, we carried out case-matching by tumor location and TNM stage, and 45 patients were selected for the analysis. Three surgeons who were experienced with conventional laparoscopic, single-port laparoscopic or robotic surgery for the treatment of colorectal disease had performed the operations. Informed consents were obtained from all the patients. Patient demographics, operative out- comes, histopathologic outcomes, including quality of TME, CRM involvement, DRM and number of harvested lymph nodes, postoperative complications, and recurrence were analyzed based on the colorectal cancer database of our institution and chart reviews. The macroscopic quality of TME specimens was assessed by a single pathologist, who specialized in colorectal disease, according to the grading system used by the American College of Surgeons Oncology Group Z6051 [21]. Median follow-up duration was 21.3 months (range, 7.9-4.7 months). This study was approved by Institutional Review Board.

\section{Operative techniques}

Technique for taTME

We applied a one-team approach in which the abdominal phase of the procedure and the subsequent transanal phase were carried out by a single surgical team. For the abdominal phase, we adopted a single or single-plus-one-port laparoscopy-assisted technique based on our previous experience with single-plus-one-port laparoscopic surgery for the treatment of rectal cancer [22]. For access into the abdominal cavity, a skin incision of $2-3 \mathrm{~cm}$ in length was created on the umbilicus or the presumed ileostomy site on the left lower quadrant of the abdomen, which is our preferred location to facilitate splenic flexure mobilization, as reported in our previous study [22]. One additional 5- or 12-mm port was placed on the right lower quadrant abdomen, as needed. Ligation of inferior mesenteric vessels and mobilization of the left-sided colon and rectosigmoid junction were carried out in the abdominal phase. For the transanal phase, we placed a Lone Star Retractor (CooperSurgical Inc., Trumbull, CT, USA) to improve exposure of the endo-anal space and installed the GelPOINT Path transanal access platform (Applied Medical Inc., Rancho Santa Margarita, CA, USA). A pneumorectum was established to a pressure of 10 $\mathrm{mmHg}$ by using a conventional gas insufflator, and a $30^{\circ}$ rigid telescope was used. The rectal lumen was closed to exclude the tumor by placing 2 purse string sutures $1 \mathrm{~cm}$ distal to the lower margin of the tumor. A full-thickness circumferential incision was made on the rectal mucosa $1 \mathrm{~cm}$ distal to the purse string suture by using a monopolar hook or energy device, and circumferential mobilization of the rectum was performed. When the dissection plane from below met the plane dissected from above, the specimen was extracted through the anal canal, and the proximal colon was prepared for an anastomosis. Depending on the length of the remaining rectal stump, a single-stapled or hand-sewn coloanal anastomosis was constructed. A draining catheter was placed through the port site on the right lower quadrant of the abdomen.

\section{Technique for robTME}

We adopted a totally robotic approach with a six-port system (da Vinci S or Si System, Intuitive Surgical Inc., Sunnyvale, CA, USA), as described in a previous study [23]. The surgical cart approached the left lower quadrant of the patient's abdomen in an oblique manner and remained in the same location during the whole proce- 
Table 1. Patients' demographics $(\mathrm{n}=45)$

\begin{tabular}{|c|c|c|c|}
\hline Clinicopathologic parameter & taTME $(n=21)$ & robTME $(n=24)$ & P-value \\
\hline Age (yr) & & & 0.059 \\
\hline$<60$ & $10(47.6)$ & $18(75.0)$ & \\
\hline$\geq 60$ & $11(52.4)$ & $6(25.0)$ & \\
\hline Sex & & & 0.124 \\
\hline Male & 16 (76.2) & 13 (54.2) & \\
\hline Female & $5(23.8)$ & $11(45.8)$ & \\
\hline ASA PS classification & & & 0.802 \\
\hline I & $8(38.1)$ & 7 (29.2) & \\
\hline$\|$ & $12(57.1)$ & $16(66.7)$ & \\
\hline III-IV & $1(4.8)$ & $1(4.1)$ & \\
\hline Body mass index $\left(\mathrm{kg} / \mathrm{m}^{2}\right)$ & $24.4 \pm 3.44$ & $23.6 \pm 3.00$ & 0.344 \\
\hline Abdominal operation history & & & 0.062 \\
\hline No & $20(95.2)$ & $18(75.0)$ & \\
\hline Appendectomy & $0(0)$ & $4(16.7)$ & \\
\hline Gynecologic surgery & $0(0)$ & $2(8.3)$ & \\
\hline Gastric surgery & $1(4.8)$ & $0(0)$ & \\
\hline Initial CEA (ng/mL) & & & 0.860 \\
\hline$<5$ & $18(85.7)$ & $21(87.5)$ & \\
\hline$\geq 5$ & $3(14.3)$ & $3(12.5)$ & \\
\hline Tumor location & & & 0.526 \\
\hline Mid & $15(71.4)$ & $15(62.5)$ & \\
\hline Lower & $6(28.6)$ & $9(37.5)$ & \\
\hline Tumor height (cm) & $6.1 \pm 1.63$ & $5.2 \pm 1.99$ & 0.096 \\
\hline cT category & & & 0.239 \\
\hline 1 & $0(0.0)$ & $1(4.2)$ & \\
\hline 2 & $3(14.3)$ & $8(33.3)$ & \\
\hline 3 & $17(81.0)$ & $15(62.5)$ & \\
\hline 4 & $1(4.8)$ & $0(0)$ & \\
\hline cN category & & & 0.262 \\
\hline 0 & $4(19.0)$ & $6(25.0)$ & \\
\hline 1 & $12(57.1)$ & 8 (33.3) & \\
\hline 2 & $5(23.8)$ & $10(41.7)$ & \\
\hline Tumor obstruction & $1(4.8)$ & $1(4.2)$ & 0.923 \\
\hline Tumor perforation & $0(0)$ & $1(4.2)$ & 0.344 \\
\hline Preoperative CCRT & & & 0.259 \\
\hline No & 7 (33.3) & $12(50.0)$ & \\
\hline Yes & $14(66.7)$ & $12(50.0)$ & \\
\hline
\end{tabular}

Values are presented as number of patients (\%) or mean \pm standard deviation. TME, total mesorectal excision; taTME, transanal TME; robTME, robotic TME; ASA PS, American Society of Anesthesiologists physical status; CEA, carcinoembryonic antigen; CCRT, concurrent chemoradiotherapy. dure. The port configuration was changed in the middle of the procedure to allow colon mobilization and TME, respectively. For cases with stapled anastomosis, the specimen was extracted though an incision that extended from the supraumbilical camera port whereas in the case of a hand-sewn coloanal anastomosis, it was retrieved through the anal canal.

\section{Statistical analyses}

Statistical analysis was conducted using Stata 12 (StataCorp LP., College Station, TX, USA). The chi-square test and the t-test were carried out for categorical and continuous variables, respectively. Differences were considered significant when the P-value was less than 0.05 .

\section{RESULTS}

The patients' demographics are summarized in Table 1 . After casematching by tumor location and TNM stage, the cases of 21 patients who had undergone a taTME and 24 patients who had undergone a robTME were analyzed. A history of previous abdominal surgery was more common in the robTME group than the taTME group. Tumor location in lower rectum was more frequently observed $(58.3 \%$ vs. $23.1 \%, \mathrm{P}=0.009)$ in the robTME group before case-matching; however, that was not true after case-matching. The $\mathrm{cT}$ category, $\mathrm{cN}$ category and history of preoperative CCRT were not different between the 2 groups.

Table 2. Operative details $(n=45)$

\begin{tabular}{lccc}
\hline Clinicopathologic parameter & taTME $(\mathrm{n}=21)$ & robTME $(\mathrm{n}=24)$ & P-value \\
\hline Anastomosis & $18(85.7)$ & $15(62.5)$ & 0.079 \\
$\quad$ Stapled & $3(14.3)$ & $9(37.5)$ & \\
$\quad$ Hand-sewn coloanal & & & 0.000 \\
Specimen extraction site & $21(100)$ & $8(33.3)$ & \\
$\quad$ Transanal & $0(0)$ & $16(66.7)$ & \\
Transabdominal & $0(0)$ & $1(4.2)$ & 0.344 \\
Open conversion & $267 \pm 77.6$ & $252 \pm 77.3$ & 0.526 \\
Operation time (min) & $283 \pm 277.6$ & $155 \pm 118.5$ & 0.061 \\
Estimated blood loss (mL) & & & 0.083 \\
Diverting ileostomy & $6(28.6)$ & $13(54.2)$ & \\
No & $15(71.4)$ & $11(45.8)$ & \\
Yes & & & 0.234 \\
lleostomy repair & $0(0)$ & $1(9.1)$ & \\
No & $15(100)$ & $10(90.9)$ & \\
Yes & $8.0 \pm 2.06$ & $8.2 \pm 6.62$ & 0.948 \\
Time to ileostomy repair (mo) & $20(95.2)$ & $22(91.7)$ & 0.632 \\
\hline Stoma free at last follow-up & & & \\
\hline
\end{tabular}

Values are presented as number of patients (\%) or mean \pm standard deviation. TME, total mesorectal excision; taTME, transanal TME; robTME, robotic TME. 
Table 3. Histopathologic and postoperative outcomes $(n=45)$

\begin{tabular}{|c|c|c|c|}
\hline Clinicopathologic parameter & taTME $(n=21)$ & robTME ( $\mathrm{n}=24)$ & P-value \\
\hline TNM stage & & & 0.283 \\
\hline 0 & $5(23.8)$ & $4(16.7)$ & \\
\hline I & $5(23.8)$ & $12(50.0)$ & \\
\hline$\|$ & $5(23.8)$ & 5 (20.8) & \\
\hline III & $6(28.6)$ & $3(12.5)$ & \\
\hline (y)pT category & & & 0.360 \\
\hline 0 & $4(19.0)$ & $2(8.3)$ & \\
\hline Tis & $0(0)$ & $2(8.3)$ & \\
\hline 1 & $4(19.0)$ & $4(16.7)$ & \\
\hline 2 & $4(19.0)$ & $9(37.5)$ & \\
\hline 3 & $8(38.1)$ & $7(29.2)$ & \\
\hline 4 & $1(4.8)$ & $0(0)$ & \\
\hline (y)pN category & & & 0.315 \\
\hline 0 & $15(71.4)$ & $21(87.5)$ & \\
\hline 1 & 5 (23.8) & 3 (12.5) & \\
\hline 2 & $1(4.8)$ & $0(0)$ & \\
\hline Size of tumor (cm) & $2.9 \pm 1.53$ & $3.0 \pm 1.67$ & 0.830 \\
\hline Proximal margin (cm) & $20.8 \pm 6.68$ & $16.0 \pm 5.92$ & 0.030 \\
\hline Distal margin (cm) & $2.2 \pm 1.28$ & $1.9 \pm 1.06$ & 0.312 \\
\hline CRM (mm) & & & 0.738 \\
\hline$>10$ & $14(66.7)$ & $17(70.8)$ & \\
\hline$>5$ and $\leq 10$ & 5 (23.8) & 3 (12.5) & \\
\hline$>1$ and $\leq 5$ & $1(4.8)$ & $2(8.3)$ & \\
\hline$\leq 1$ & $1(4.8)$ & $2(8.3)$ & \\
\hline Macroscopic quality of TME & & & 0.122 \\
\hline Complete & 19 (90.5) & $24(100)$ & \\
\hline Nearly complete & 2 (9.5) & $0(0)$ & \\
\hline Incomplete & $0(0)$ & $0(0)$ & \\
\hline Number of retrieved lymph nodes & $10.7 \pm 6.28$ & $13.6 \pm 6.29$ & 0.123 \\
\hline Length of stay (day) & $8.0 \pm 4.86$ & $7.7 \pm 3.22$ & 0.813 \\
\hline Overall complications & $6(28.6)$ & 7 (29.2) & 0.965 \\
\hline Anastomotic leak & 1 & 3 & 0.363 \\
\hline Voiding difficulty & 2 & 1 & 0.472 \\
\hline Anastomotic bleeding & 1 & - & \\
\hline lleus & - & 1 & \\
\hline Wound infection & - & 1 & \\
\hline Pulmonary & 1 & 1 & \\
\hline Delirium & 1 & - & \\
\hline CD classification & & & 0.989 \\
\hline 1 & $2(9.5)$ & $3(12.5)$ & \\
\hline$\|$ & $2(9.5)$ & $2(8.3)$ & \\
\hline Illa & $0(0)$ & $0(0)$ & \\
\hline Illb & $2(9.5)$ & $2(8.3)$ & \\
\hline
\end{tabular}

Values are presented as number of patients (\%) or mean \pm standard deviation. TME, total mesorectal excision; taTME, transanal TME; robTME, robotic TME; CRM, circumferential resection margin; CD classification, Clavien-Dindo classification of postoperative complication.
Table 4. Recurrence pattern $(\mathrm{n}=45)$

\begin{tabular}{lccc}
\hline Clinicopathologic parameter & taTME $(\mathrm{n}=21)$ & robTME $(\mathrm{n}=24)$ & P-value \\
\hline Median follow-up (mo) & 20.1 & 22.0 & 0.351 \\
Overall recurrence & $2(9.5)$ & $1(4.8)$ & 0.472 \\
Local recurrence & $1(4.8)$ & $0(0)$ & 0.280 \\
Distant recurrence & $2(9.5)$ & $1(4.2)$ & 0.472 \\
$\quad$ Lung and Paraaortic LN & 1 & 1 & \\
$\quad$ Liver & 1 & - & \\
\hline
\end{tabular}

Values are presented as number of patients (\%) unless otherwise indicated.

In terms of operative details, a hand-sewn coloanal anastomosis was more common in the robTME group ( $37.5 \%$ vs. $14.3 \%$ ), with intermediate significance (0.079). The specimen was extracted through the anus in $100 \%$ of the patients in the taTME group compared with $33.3 \%$ in the robTME group. Estimated blood loss (EBL) was greater with a taTME than a robTME $(283 \mathrm{~mL}$ vs. $155 \mathrm{~mL}, \mathrm{P}$ $=0.061)$. The rate of diverting loop-ileostomy was higher in the taTME group (71.4\% vs. $45.8 \%$ ), but that difference was not statistically significant. The rate of ileostomy repair and the time to ileostomy were not different between the groups (Table 2).

The histopathologic and the postoperative outcomes are summarized in Table 3. The proximal resection margin (PRM) was longer for a taTME than a robTME $(20.8 \mathrm{~cm}$ vs. $16.0 \mathrm{~cm})$. The DRM, CRM involvement, completeness of TME, and number of harvested lymph nodes were not different between the 2 groups. The overall complication rate was not different. The anastomotic leak rate was higher in the robTME group (12.5\%) than in the taTME group (4.8\%), but that difference was not statistically significant. The rates of voiding difficulty and grade III or higher complication according to the Clavien-Dindo classification were not different between the 2 groups.

With a median follow-up duration of 21.3 months, 2 patients in the taTME group and 1 in the robTME group experienced recurrences: Of the 2 patients in the taTME group, 1 had both local and distant recurrences at the pelvic side wall, liver, and lung while the other showed paraaortic and aortocaval lymph node metastases. The patient in the robTME group had lung metastases (Table 4).

\section{DISCUSSION}

The current study demonstrated that transanal endoscopic and transabdominal robTME did not show differences with respect to intra- and postoperative outcomes, histopathologic outcomes, and recurrence. The exceptions were greater EBL (measurement of blood in the surgical suction container and visual estimation of the blood on surgical sponges and laparotomy pads) and larger DRM in the taTME group.

We compared taTME and robTME, 2 surgical approaches with potential to overcome the limitations of conventional laparoscopic surgery for the treatment of rectal cancer, with respect to the short- 
term postoperative and oncologic outcomes. This study has several limitations. It is a single-center study with a retrospective design, so it inevitably has selection and information bias. The 2 groups were not comparable in terms of the location of the tumor; the robTME group had a higher proportion of low rectal lesions. For that reason, case-matching with the variables of tumor location and TNM stage was carried out. As the sample size was small, we could not focus on high-risk groups of patients, such as those with high BMI, large tumor size, or a history of irradiated rectal cancer. Thus, the study results might be underpowered. Finally, the degree of contribution made by the 3 surgeons to each surgical procedure varied. The taTME cases represent one surgeon's initial experience whereas three-fourths of the robTME cases represent the accumulated experience of another surgeon.

In this study, before case-matching, the locations of tumor were different between the 2 groups: a higher proportion of low rectum lesions in the robTME group and of mid-rectum lesions in the taTME group. In our institution, we tend to recommend robotic surgery more strongly to patients with low rectal cancer than to those with upper- or mid-rectal cancer because we believe that the technical advantages of a surgical robot might be more beneficial to patients who have low rectal lesions. One clinical advantage of robotic surgery is a lower rate of conversion to open surgery compared to laparoscopy. A nationwide study from the United States and meta-analysis report demonstrated that robotic surgery for the treatment of rectal cancer showed a lower conversion rate [3] and that the beneficial effect might be greater for patients with low rectal cancer [6]. When we started to perform taTME, patients with mid-rectal lesion were selected because of the necessity to dissect in advance around the tumor-bearing area in the anal canal and/or on the pelvic floor with an open approach to properly place a transanal device into the anal canal and this initial surgical step being considered time-consuming and challenging for beginners with the possibility of implantation of cancer cells by tumor manipulation. Even though the 2 groups became comparable in terms of tumor location after case-matching, coloanal anastomosis was more common in the robTME group, reflecting the relatively lower tumor height in the robTME group $(5.2 \mathrm{~cm}$ vs. $6.1 \mathrm{~cm})$. All patients in the taTME group had specimens extracted through the anus whereas in the robTME group, the specimens were extracted though the anus only for patients who underwent handsewn coloanal anastomoses. Several studies reported that transanal specimen extraction following laparoscopic or robotic rectal cancer surgery is a safe and feasible procedure without an increased local recurrence rate $[24,25]$.

The operation time is known to be reduced with taTME, especially when the abdominal and the transanal procedures are conducted at the same time by 2 surgical teams $[18,19]$ whereas robotic surgery is known to be associated with a longer operation time than conventional laparoscopy, in part because of the set-up time $[6,9-11]$. In this study, however, the operation times for the taTME and the robTME were not significantly different. First, we carried out the abdominal and the transanal procedures in a sequential manner for the taTME because on a practical level, having 2 surgical teams for a single case was not easy. Second, the taTME patients represented the initial experience of a surgeon whereas the robTME patients represented the accumulated experience of another surgeon. The greater EBL in taTME may be related to this difference. The rate of diverting stoma formation was higher in the taTME than the robTME (71.4\% vs. $45.8 \%)$ group, but without statistical significance. This may be due to the surgeon who performed the taTME having been in the learning period and thus having had a tendency to make a protective stoma more frequently. The lower anastomotic leak rate may be related to this difference. However, making a rational inference is difficult because of the limited number of cases.

In our study, patients in the taTME group showed a longer PRM than those in the robTME group $(20.8 \mathrm{~cm}$ vs. $16.0 \mathrm{~cm}, \mathrm{P}=0.030)$, but no difference was observed in the DRM. Several studies that compared taTME and conventional laparoscopic TME reported that taTME was associated with a significantly longer DRM (2.8 $\mathrm{cm}$ vs. $1.7 \mathrm{~cm}$ or $2.4 \mathrm{~cm}$ vs. $1.5 \mathrm{~cm}$ ) $[18,19]$. The explanation for this was that the division level of the distal rectum in taTME is controlled by direct visualization of the endoluminal lesion whereas for laparoscopic TME, multiple firings of staplers and rectal division in an oblique line occur due to the limited angulation, compromising the optimal DRM. In contrast, other studies have shown no difference in the DRM between taTME and laparoscopic TME $[20,26,27]$. Most studies that evaluated robotic surgery for the treatment of rectal cancer compared to the conventional laparoscopic technique demonstrated no difference in the DRM [9-11]. However, we must investigate the clinical impact of a new stapling device designed exclusively for the surgical robot that is known to have a wider range of articulation and be capable of providing feedback for proper tissue-clamping. For taTME patients, the mobilization of the splenic flexure was done for all patients, so extracting the specimen through the anus was essential. This may be related to the longer PRM in the taTME group in our study.

Involvement of the CRM and incomplete TME quality are predictors of local recurrence after radical surgery for rectal cancer. In this study, the rate of CRM involvement and complete TME quality were not different between groups. Previous studies reported low rates of involved CRM and/or excellent TME qualities with taTME [17-20]. A randomized clinical trial that compared transanal to transabdominal dissection of the rectum during laparoscopic surgery for low rectal cancer reported a lower rate of CRM involvement with transanal dissection than with transabdominal dissection ( $4 \%$ vs. $18 \%, \mathrm{P}=0.025$ ), although the transanal surgery was not an endoscopic approach [28]. Other studies that compared robotic and conventional laparoscopic surgery for rectal cancer reported comparable and excellent CRM involvement rates or better TME quality, showing no difference in the local recurrence rates $[5,10,29,30]$. 
To the best of our knowledge, this is the first study to evaluate transanal endoscopic and transabdominal robTME, 2 different surgical approaches considered to have the potential to overcome the limitations of conventional laparoscopic techniques. Future studies are required to compare long-term oncologic and functional outcomes and perform cost analyses. Such studies should have a prospective design and, especially, include high-risk groups of patients with irradiated and/or low rectal cancer, large tumor size, high BMI, or narrow pelvis.

In conclusion, transanal endoscopic and transabdominal robTME showed similar intra- and postoperative outcomes, with the exception of greater EBL in taTME. The rate of CRM involvement, the TME quality, and the DRM were comparable, but the PRM was longer in the taTME group than the robTME group. Over a median follow-up period of 21.3 months, the recurrence rate was not different between the 2 groups.

\section{CONFLICT OF INTEREST}

No potential conflict of interest relevant to this article was reported.

\section{REFERENCES}

1. Stevenson AR, Solomon MJ, Lumley JW, Hewett P, Clouston AD, Gebski VJ, et al. Effect of laparoscopic-assisted resection vs open resection on pathological outcomes in rectal cancer: The ALaCaRT randomized clinical trial. JAMA 2015;314:1356-63.

2. Fleshman J, Branda M, Sargent DJ, Boller AM, George V, Abbas M, et al. Effect of laparoscopic-assisted resection vs open resection of stage II or III rectal cancer on pathologic outcomes: The ACOSOG Z6051 randomized clinical trial. JAMA 2015;314:1346-55.

3. Halabi WJ, Kang CY, Jafari MD, Nguyen VQ, Carmichael JC, Mills S, et al. Robotic-assisted colorectal surgery in the United States: a nationwide analysis of trends and outcomes. World J Surg 2013; 37:2782-90.

4. Trastulli S, Farinella E, Cirocchi R, Cavaliere D, Avenia N, Sciannameo F, et al. Robotic resection compared with laparoscopic rectal resection for cancer: systematic review and meta-analysis of short-term outcome. Colorectal Dis 2012;14:e134-56.

5. Baik SH, Kwon HY, Kim JS, Hur H, Sohn SK, Cho CH, et al. Robotic versus laparoscopic low anterior resection of rectal cancer: short-term outcome of a prospective comparative study. Ann Surg Oncol 2009;16:1480-7.

6. Ielpo B, Caruso R, Quijano Y, Duran H, Diaz E, Fabra I, et al. Robotic versus laparoscopic rectal resection: is there any real difference? A comparative single center study. Int J Med Robot 2014; 10:300-5.

7. Erguner I, Aytac E, Boler DE, Atalar B, Baca B, Karahasanoglu T, et al. What have we gained by performing robotic rectal resection? Evaluation of 64 consecutive patients who underwent laparoscopic or robotic low anterior resection for rectal adenocarcinoma.
Surg Laparosc Endosc Percutan Tech 2013;23:316-9.

8. Bianchi PP, Ceriani C, Locatelli A, Spinoglio G, Zampino MG, Sonzogni A, et al. Robotic versus laparoscopic total mesorectal excision for rectal cancer: a comparative analysis of oncological safety and short-term outcomes. Surg Endosc 2010;24:2888-94.

9. Cho MS, Baek SJ, Hur H, Min BS, Baik SH, Lee KY, et al. Short and long-term outcomes of robotic versus laparoscopic total mesorectal excision for rectal cancer: a case-matched retrospective study. Medicine (Baltimore) 2015;94:e522.

10. Park JS, Choi GS, Lim KH, Jang YS, Jun SH. S052: a comparison of robot-assisted, laparoscopic, and open surgery in the treatment of rectal cancer. Surg Endosc 2011;25:240-8.

11. Kang J, Yoon KJ, Min BS, Hur H, Baik SH, Kim NK, et al. The impact of robotic surgery for mid and low rectal cancer: a case-matched analysis of a 3-arm comparison--open, laparoscopic, and robotic surgery. Ann Surg 2013;257:95-101.

12. Park SY, Choi GS, Park JS, Kim HJ, Ryuk JP, Yun SH. Urinary and erectile function in men after total mesorectal excision by laparoscopic or robot-assisted methods for the treatment of rectal cancer: a case-matched comparison. World J Surg 2014;38:1834-42.

13. Luca F, Valvo M, Ghezzi TL, Zuccaro M, Cenciarelli S, Trovato C, et al. Impact of robotic surgery on sexual and urinary functions after fully robotic nerve-sparing total mesorectal excision for rectal cancer. Ann Surg 2013;257:672-8.

14. Kim JY, Kim NK, Lee KY, Hur H, Min BS, Kim JH. A comparative study of voiding and sexual function after total mesorectal excision with autonomic nerve preservation for rectal cancer: laparoscopic versus robotic surgery. Ann Surg Oncol 2012;19:2485-93.

15. Telem DA, Han KS, Kim MC, Ajari I, Sohn DK, Woods K, et al. Transanal rectosigmoid resection via natural orifice translumenal endoscopic surgery (NOTES) with total mesorectal excision in a large human cadaver series. Surg Endosc 2013;27:74-80.

16. de Lacy AM, Rattner DW, Adelsdorfer C, Tasende MM, Fernández M, Delgado S, et al. Transanal natural orifice transluminal endoscopic surgery (NOTES) rectal resection: "down-to-up" total mesorectal excision (TME)--short-term outcomes in the first 20 cases. Surg Endosc 2013;27:3165-72.

17. Lacy AM, Tasende MM, Delgado S, Fernandez-Hevia M, Jimenez M, De Lacy B, et al. Transanal total mesorectal excision for rectal cancer: outcomes after 140 patients. J Am Coll Surg 2015;221:41523.

18. Chen CC, Lai YL, Jiang JK, Chu CH, Huang IP, Chen WS, et al. Transanal total mesorectal excision versus laparoscopic surgery for rectal cancer receiving neoadjuvant chemoradiation: a matched case-control study. Ann Surg Oncol 2016;23:1169-76.

19. Fernández-Hevia M, Delgado S, Castells A, Tasende M, Momblan D, Díaz del Gobbo G, et al. Transanal total mesorectal excision in rectal cancer: short-term outcomes in comparison with laparoscopic surgery. Ann Surg 2015;261:221-7.

20. Velthuis S, Nieuwenhuis DH, Ruijter TE, Cuesta MA, Bonjer HJ, Sietses C. Transanal versus traditional laparoscopic total mesorectal excision for rectal carcinoma. Surg Endosc 2014;28:3494-9. 
21. Nagtegaal ID, van de Velde CJ, van der Worp E, Kapiteijn E, Quirke P, van Krieken JH, et al. Macroscopic evaluation of rectal cancer resection specimen: clinical significance of the pathologist in quality control. J Clin Oncol 2002;20:1729-34.

22. Jung KU, Yun SH, Cho YB, Kim HC, Lee WY, Chun HK. Single incision and reduced port laparoscopic low anterior resection for rectal cancer: initial experience in 96 cases. ANZ J Surg 2016;86: 403-7.

23. Park YA, Kim JM, Kim SA, Min BS, Kim NK, Sohn SK, et al. Totally robotic surgery for rectal cancer: from splenic flexure to pelvic floor in one setup. Surg Endosc 2010;24:715-20.

24. Kang J, Min BS, Hur H, Kim NK, Lee KY. Transanal specimen extraction in robotic rectal cancer surgery. Br J Surg 2012;99:133-6.

25. Franklin ME Jr, Liang S, Russek K. Integration of transanal specimen extraction into laparoscopic anterior resection with total mesorectal excision for rectal cancer: a consecutive series of $179 \mathrm{pa}-$ tients. Surg Endosc 2013;27:127-32.

26. Chouillard E, Regnier A, Vitte RL, Bonnet BV, Greco V, Chahine
E, et al. Transanal NOTES total mesorectal excision (TME) in patients with rectal cancer: is anatomy better preserved? Tech Coloproctol 2016;20:537-44.

27. Rasulov AO, Mamedli ZZ, Gordeyev SS, Kozlov NA, Dzhumabaev HE. Short-term outcomes after transanal and laparoscopic total mesorectal excision for rectal cancer. Tech Coloproctol 2016;20: 227-34.

28. Denost Q, Adam JP, Rullier A, Buscail E, Laurent C, Rullier E. Perineal transanal approach: a new standard for laparoscopic sphincter-saving resection in low rectal cancer, a randomized trial. Ann Surg 2014;260:993-9.

29. Kwak JM, Kim SH, Kim J, Son DN, Baek SJ, Cho JS. Robotic vs laparoscopic resection of rectal cancer: short-term outcomes of a case-control study. Dis Colon Rectum 2011;54:151-6.

30. Baek JH, Pastor C, Pigazzi A. Robotic and laparoscopic total mesorectal excision for rectal cancer: a case-matched study. Surg Endosc 2011;25:521-5. 